\title{
Pyrrolizidine alkaloid toxicosis and hepatic encephalopathy in horses in Easter Island, Chile
}

\author{
Jorge C. Lohse ${ }^{\text {ab* }}$ Enrique Paredes ${ }^{\mathrm{c}}$, Carlos M. González ${ }^{\mathrm{d}}$, \\ Marc Koene $^{\mathrm{e}}$, Mahmoud Mageed $^{\mathrm{e}}$
}

\begin{abstract}
A group of horses died in Easter Island following anorexia, weight loss and neurological signs. Similar cases have occurred since the introduction of a plant containing pirrolizidine alkaloid to the island. This study describes the grazing behaviour of the horses and the potential correlation with the development of these horses clinical signs.

Key words: pyrrolizidine alkaloid, Crotalaria spp., hepatopathy, monocrotaline.
\end{abstract}

Easter Island (Rapa Nui) is located at $3,700 \mathrm{~km}$ west of the Chilean Pacific Coast (277'10'S 109²1'17'O), it has an area of 16,628 hectares and a population of over 2,300 horses (Montoya 2011). Extensive soil erosion was noticed in the late 1970's, and Crotalaria grahamiana was introduced by National Forest Corporation to prevent further damage to the landscape (Etienne et al 1982, Dubois et al 2013). The plant thrived and invaded the island, being described in the areas of Mataveri, Rano Kau, Vinapu, Rano Raraku and Poike (Dubois et al 2013), and since the early 1980's the islanders observed that horses (any age and sex) that consumed C. grahamiana eventually died from anorexia, weight loss and neurological signs, with locals referring to them as "crazy horses" $(\mathrm{CH})$. Cases occur all year round with a peak of mortality rate during the summer (December to February) (Artz and Mount 1999). A case report on pyrrolizidine alkaloid (PA) toxicity in a horse in this island was reported by Artz and Mount (1999).

The consumption of plants containing PAs can cause intoxication and the development of clinical signs due to liver damage, neurotoxicity, cardiac and pulmonary problems in livestock and wildlife (Fu et al 2002). Also, genetic mutation and embriotoxicity were reported ( $\mathrm{Fu}$ et al 2002, Stegelmeier 2011). In humans, veno-occlusive hepatic disease has been reported (Stegelmeier et al 1999, Fu et al 2002, Stegelmeier 2011).

The mechanisms of hepatotoxicity due to PA include multiple pathways such as activation of pyrrolic ester, which in turn is catalysed by the hepatic cytochrome P450 enzyme

Accepted: 23.01.2018.

aprograma Doctorado en Medicina Veterinaria, Facultad de Ecología y Recursos Naturales, Universidad Andrés Bello, Santiago, Chile.

${ }^{b}$ Escuela de Ciencias Veterinarias, Universidad Viña del Mar, Viña del Mar, Chile.

'Instituto de Patología Animal, Facultad de Ciencias Veterinarias, Universidad Austral de Chile, Valdivia, Chile.

dEscuela de Medicina Veterinaria, Facultad de Ecología y Recursos Naturales, Universidad Andrés Bello, Santiago, Chile.

'Tierklinik Lüsche Essener Str. 39a D-49456 Bakum, Germany.

*Corresponding author: J Lohse; Campus UVM Rodelillo, Av.Agua Santa 7055, Viña del Mar, Chile; lohse.j@gmail.com system (CYP450), production of reactive oxygen species (ROS) and GSH-metabolising enzymes (Stegelmeier et al 2016, Yan et al 2016). PAs have been identified in over 6,000 plants of the genus Senecio, Crotalaria, Heliotropum and Echium (Stegelmeier 2011). C. grahamiana and $C$. pallida have been identified in Easter Island, and it has been suggested that $\mathrm{CH}$ cases might be the consequence of the animals consuming these plants (Artz and Mount 1999). C. pallida was described in the island since 1913 (Dubois et al 2013).

The role of PAs as the causative agent of $\mathrm{CH}$ in Easter Island has not been thoroughly investigated. The objective of this study is to record the distribution of Crotalaria spp. in this island, the grazing behaviour of horses and to establish any potential correlation between the consumption of those plants and the appearance of the clinical signs described as $\mathrm{CH}$. This prospective study was performed between the years 2010 and 2015, and was approved by the Ethics Committee of Universidad Viña del Mar (11/13/2012). The distribution of C. grahamiana and $C$. pallida across the Easter Island was recorded by semi-systematic observation on each trip. Grazing habits were monitored following a group of 10 horses during 10 days chosen randomly on each trip by one researcher, during the summer of 2010 and 2011, autumn 2013 and summer 2014, due to the islanders tradition of letting horses roam freely through the Island. Eight horses (H1 to H8) (6 geldings and 2 mares), ponies, aged between 2-15 years (mean 10 years) and body weight ranging from 250-320 kg, were selected through nonprobability sampling with the neurological clinical signs described as $\mathrm{CH}$ by Artz and Mount (1999), these animals had been observed consuming Crotalaria spp. Clinical examination, complete blood cell count ${ }^{1}$ and serum biochemistry profiles ${ }^{2}$ (LQCE laboratory, Santiago) were performed in 2014 (H1 to H8). Ammonia blood levels were measured in plasma samples

\footnotetext{
Wierner Lab Group. Rosario, Argentina.

2 BioSystems BA 400®. BioSystems S.A., Barcelona. España.
} 
by enzymatic assay ${ }^{3}$ (UC-Christus Laboratory). Urine samples were analysed using Multistix strips ${ }^{4}$, and specific gravity was determined using a refractometer (ATC model 311). Liver ultrasonography was performed in all horses using convex 2.5-3.5 MHz transducer (Mindray) ${ }^{5}$. Liver biopsies were obtained using a Tru-cut $14 \mathrm{G}-15 \mathrm{~cm}$ needle biopsy under ultrasound guidance $(n=5)$. Three horses were euthanised due to severe clinical signs consistent with $\mathrm{CH}$, and postmortem examination was performed ${ }^{6}$. Tissues from liver, lung, brain, spleen and kidney were collected, fixed in $10 \%$ buffered formalin and processed for routine histological analysis. Total of liver samples $(n=8)$ were scored by a pathologist using a semi-quantitative scale as previously described (Universidad Austral de Chile, Valdivia). Additionally, immunohistochemical staining for proliferating cell nuclear antigen (PCNA), a marker of cell proliferation, was performed in liver tissues according to the manufacturer's instructions ${ }^{7}$. A terminal deoxynucleotidyl transferase dUTP Nick End Labeling assay (TUNEL) ${ }^{8}$ for the detection of apoptosis was performed. Crotalaria spp. samples were collected from areas with occurrence of $\mathrm{CH}$ cases and submitted for toxicological analysis. Gas chromatography mass spectrometry analysis (GC/MS $)^{9}$ for qualitative analysis of PAs in Crotalaria spp. samples from this island, quantitative of Monocrotaline $\left(\mathrm{MCT}^{10}\right)$ in Crotalaria spp., liver biopsies and urine from the studied horses, were carried out. Descriptive statistical analysis was performed, and Spearman's correlation coefficient was used to determine the correlation between MCT's concentrations in Crotalaria spp. and in liver biopsies $(P<0.01)$.

C. grahamiana was found throughout the Island including the areas Puna Pau, Ahu Akivi, Ahu Te Peu, Ahu Nau Nau and Rano Aroi in addition to the areas reported by Dubois et al (2013), except for the north part (Maunga Tere Vaka). This current distribution is larger than previously reported (Artz and Mount 1999, Dubois et al 2013). C. pallida was observed mainly in some areas of Vinapu and Rano Raraku. The factors responsible for the propagation of $C$. grahamiana remain unknown.

During our study in Easter Island between 2010 and 2014, horses were observed grazing $C$. grahamiana all year

\footnotetext{
3 Glutamate dehydrogenase/Cobas c311, Roche Diagnostics GmbH, Manheim, Germany.

4 Multistix 10 SG Reagent Strips. Siemens Healthcare Diagnostics Inc. USA.

5 Shenzhen Mindray Bio-Medical Electronics Co., Ltd.

6 Euthanasia solution T-61TM, Intervet Chile Ltda. Previously Xilazine $0.5 \mathrm{mg} / \mathrm{kg}$ and Ketamine $2.2 \mathrm{mg} / \mathrm{Kg}$

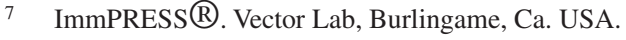

8 ApopTag@. Merck Millipore, Darmstadt, Germany.

9 Shimadzu Corporation. Tokyo, Japan.

10 Crotaline C2401 Sigma-Aldrich Co. Llc.TM St. Louis, MO, USA
}

round, this is contrary to the reports of Artz and Mount (1999) who mention that it is only consumed during the period of food shortage in the summer.

On physical examination, horses had poor body condition scores (Henneke system), jaundice and congested mucous membranes (7/8), mild to moderated dehydration $(6-8 \%)(5 / 8)$, in addition to anorexia, tachycardia, secondary photosensitization or hepatogenous, ataxia (3-5 Mayhew's grading system), obtundation and negative menace response (4/8) (table 1). The serum biochemistry profile and urinalysis revealed an increase of AST, GGT, ALP, hypoalbuminemia, plasma hyperammonemia and bilirubinuria (table 2). These clinical signs and all of these changes in the reference values suggest liver alterations (Botha et al 2012, Lecocq and Moreira 2006, Stegelmeier et al 2016). The liver sonography showed increased heterogeneity, echogenicity and bile duct dilatation in all horses.

On necropsy, jaundice, petechiae and ecchymosis of subcutaneous tissue was observed. The liver was enlarged, congested, firm with rounded edges and hemorrhagic areas with an irregular yellowish-brown surface and white foci proliferation on the diaphragmatic surface $(\mathrm{H} 1, \mathrm{H} 5, \mathrm{H} 6)$. The spleen had multiple ecchymosis and the mucous membranes of the stomach were edematous with moderate distension $(\mathrm{H} 1, \mathrm{H} 5, \mathrm{H} 6)$. All these findings are consistent with PAs intoxication in horses (Artz and Mount 1999, Santos et al 2008, Stegelmeier et al 2016). Liver histological analysis (H1-H8) revealed a mild to moderate fibrosis (8/8), mild to moderate hepatocellular megalocytosis $(7 / 8)$, mild to moderate bile duct hyperplasia (6/8), mild to severe pigment deposition (6/8), mild to moderate degenerative damage and inflammatory cell infiltration (5/8), and mild to severe tissue necrosis (3/8). All of these alterations show hepatopathy by PAs toxicosis, characteristic and highly suggestive of the condition but not pathognomonic as described in previous reports (Artz and Mount 1999, Santos et al 2008, Stegelmeier et al 2016). Brain histopathology revealed congestion and presence of enlarged astrocytes with enlarged core and vesicular appearance, probably induced by hyperammonemia (Albrecht and Norenberg 2006).

The immunohistochemistry of liver biopsies were positive to PCNA in 5/8 horses ( $\mathrm{H} 2, \mathrm{H} 3, \mathrm{H} 4, \mathrm{H} 7, \mathrm{H} 8)$, suggesting that the hepatocyte proliferation was an attempt to restore the liver mass. Increase of apoptosis, indicated by a positive to TUNEL assay, was only observed in horses that were euthanised. The potential role of PAs to induce apoptosis by a mitochondrial pathway has been suggested (Yang et al 2017). The qualitative analysis of PAs in Crotalaria spp. with GC/MS were: $93 \%$ indolizidine, $89 \%$ MCT, $74 \%$ jacozine and $72 \%$ to jacobine, seneciphiline and integerrimine; further investigations are needed to quantify them. The quantitative analysis revealed a concentration of 1.04 to $310.17 \mu \mathrm{g} / \mathrm{g}$ in C. grahamiana and 0.06 to 1.04 $\mu \mathrm{g} / \mathrm{g}$ in C. pallida plants, 0.014 to $0.137 \mu \mathrm{g} / \mathrm{g}$ in the liver, and $2.47 \mathrm{ppm}$ in the urine. These concentrations were 
Table 1. Clinical signs of Crazy Horse disease in horses of Easter Island $(n=8)$.

\begin{tabular}{|c|c|c|c|c|c|c|c|c|c|}
\hline Variable & $\mathrm{H} 1$ & $\mathrm{H} 2$ & $\mathrm{H} 3$ & $\mathrm{H} 4$ & H5 & H6 & $\mathrm{H} 7$ & $\mathrm{H} 8$ & RI \\
\hline Heart rate (bpm) & 36 & 28 & 64 & 60 & 28 & 68 & 68 & 30 & $25-50$ \\
\hline $\begin{array}{l}\text { Respiratory rate (breaths/ } \\
\text { min) }\end{array}$ & 8 & 12 & 8 & 10 & 10 & 8 & 14 & 12 & $8-18$ \\
\hline Temperature ${ }^{\circ} \mathrm{C}$ & 37.2 & 36.9 & 37.8 & 37.3 & 37 & 38.1 & 37.6 & 37.3 & $37.2-38.3$ \\
\hline Body condition & 2 & 3 & 2 & 2 & 3 & 3 & 3 & 2 & $1-9$ \\
\hline Anorexia-hyporexia & $X$ & - & $X$ & - & $\mathrm{X}$ & $\mathrm{X}$ & - & - & \\
\hline Photosensitivity & - & - & $X$ & - & $\mathrm{X}$ & $X$ & - & $\mathrm{X}$ & \\
\hline Hyperemic mucosae & $X$ & $X$ & $X$ & - & $X$ & $X$ & $X$ & $X$ & \\
\hline Jaundice & $X$ & $X$ & $X$ & $\mathrm{X}$ & - & $X$ & $\mathrm{X}$ & $X$ & \\
\hline Dehydration & $\mathrm{X}$ & - & - & $\mathrm{X}$ & $\mathrm{X}$ & $X$ & $\mathrm{X}$ & - & \\
\hline Ataxia & $X$ & - & - & - & $X$ & $X$ & $X$ & - & \\
\hline Obtundation & $X$ & - & - & $X$ & $X$ & - & $X$ & - & \\
\hline
\end{tabular}

H: Horse; RI=Reference interval; LRL=Low RI; URL=Upper RL; “-”: negative; "X”: positive.

Table 2. Results of blood analysis, urinalysis and liver ultrasound associated with pyrrolizidine alkaloid ingestion from Crotalaria grahamiana in horses of Easter Island $(n=8)$.

\begin{tabular}{|c|c|c|c|c|c|c|c|c|c|c|c|}
\hline Parameters & $\mathrm{H} 1$ & $\mathrm{H} 2$ & $\mathrm{H} 3$ & $\mathrm{H} 4$ & H5 & H6 & $\mathrm{H} 7$ & $\mathrm{H} 8$ & Mean \pm SD & $\mathrm{CV}(\%)$ & $\begin{array}{c}\text { RI } \\
\text { LRL-URL }\end{array}$ \\
\hline \multicolumn{12}{|l|}{ Blood analysis* } \\
\hline $\mathrm{RBC}\left(\mathrm{x} 10^{6} / \mu \mathrm{l}\right)$ & 5.7 & 5.5 & 6.6 & 6.6 & 7.7 & 7.9 & 6.1 & 6.2 & $6.6 \pm 0.9$ & 0.1 & $6-12$ \\
\hline Haemoglobine (\%) & 11.1 & 9.3 & 11.4 & 11.4 & 14.2 & 13.9 & 10.4 & 10.7 & $11.6 \pm 1.7$ & 0.1 & $10-18$ \\
\hline Haematocrit $(\%)$ & 31.7 & 25.7 & 32.7 & 31.7 & 40 & 39.7 & 30.4 & 30.8 & $32.8 \pm 4.8$ & 0.1 & $32-48$ \\
\hline $\mathrm{WBC}\left(\mathrm{x} 10^{9} / \mathrm{L}\right)$ & 12.6 & 5.0 & 7.1 & 7.5 & 8.3 & 13.4 & 6.4 & 7.3 & $8.5 \pm 3.0$ & 0.3 & $5.3-11.0$ \\
\hline S. neutrophils (x109/L) & 6.6 & 2.7 & 4.0 & 3.5 & 6.6 & 12.3 & 3.2 & 4.7 & $5.5 \pm 3.1$ & 0.5 & $2.1-6.0$ \\
\hline Lymphocytes (x109/L) & 4.1 & 1.5 & 1.9 & 3.0 & 1.2 & 0.6 & 2.5 & 1.8 & $2.1 \pm 1.1$ & 0.5 & $1.5-5.0$ \\
\hline Eosinophils (x109/L) & 0.3 & 0.1 & 0 & 0.7 & 0 & 0 & 0.2 & 0.7 & $0.3 \pm 0.3$ & 1.1 & $0-0.8$ \\
\hline Monocytes (x109/L) & 0.2 & 0 & 0.1 & 0 & 0 & 0 & 0.1 & 0.1 & $0.1 \pm 0.1$ & 1.1 & $0-0.6$ \\
\hline Thrombocyte (x109/L) & 210 & 146 & 167 & 117 & 133 & 158 & 131 & 119 & $147.6 \pm 30.8$ & 0.2 & $90-210$ \\
\hline BUN (mg/dl) & 7 & 10 & 7.9 & 9.1 & 6.9 & 7 & 7.5 & 7.9 & $7.9 \pm 1.1$ & 0.1 & $8-27$ \\
\hline Creat (mg/dl) & 1.3 & 1.2 & 1.2 & 0.9 & 1.0 & 1.2 & 1.6 & 1.7 & $1.3 \pm 0.3$ & 0.2 & $1.2-1.9$ \\
\hline $\operatorname{ALP}(\mathrm{U} / \mathrm{L})$ & 903 & 1000 & 926 & 2046 & 1060 & 3283 & 2077 & 935 & $1528.8 \pm 866.2$ & 0.5 & $70.1-226.8$ \\
\hline AST (U/L) & 516 & 670 & 453 & 527 & 399 & 525 & 423 & 623 & $517 \pm 93.9$ & 0.2 & $226-366$ \\
\hline GGT (U/L) & 1368 & 50 & 269 & 1368 & 199 & 77 & 47 & 201 & $447.4 \pm 573.8$ & 1.2 & $4.3-13.4$ \\
\hline CK (U/L) & 1903 & 1785 & 261 & 375 & 621 & 527 & 923 & 243 & $829.8 \pm 663.6$ & 0.7 & $160-330$ \\
\hline Proteins (g/dL) & 6.1 & 8.5 & 6.9 & 8.2 & 7.5 & 8 & 7.3 & 7.9 & $7.6 \pm 0.8$ & 0.1 & $5.2-7.9$ \\
\hline Albumin (g/dL) & 1.9 & 1.5 & 2.2 & 1.9 & 3.1 & 2 & 2.1 & 2.2 & $2.1 \pm 0.5$ & 0.2 & $2.6-3.7$ \\
\hline Globulin (g/dL) & 4.2 & 5.2 & 4.7 & 5.4 & 4.4 & 4.8 & 5 & 5.7 & $4.9 \pm 0.5$ & 0.1 & $2.6-4.0$ \\
\hline Total bilirubin (mg/dL) & 1.0 & 0.8 & 3.6 & 1.0 & 2.9 & 4 & 4.3 & 3.2 & $2.6 \pm 1.5$ & 0.5 & $0.3-3.0$ \\
\hline Ammonia (umol/L) & 363 & 40 & 33 & 19 & 431 & 345 & NO & $\mathrm{NO}$ & $153.9 \pm 189.1$ & 1.1 & $4-49$ \\
\hline \multicolumn{12}{|l|}{ Urinalysis** } \\
\hline Protein & $\mathrm{L}$ & $\mathrm{L}$ & - & - & - & - & $\mathrm{NO}$ & $\mathrm{NO}$ & & & $-/ \mathrm{T}$ \\
\hline Occult Blood & M & - & - & - & - & M & $\mathrm{NO}$ & $\mathrm{NO}$ & & & - \\
\hline Glu(mg/dL) & 1000 & 250 & - & - & - & 1000 & NO & $\mathrm{NO}$ & & & - \\
\hline $\mathrm{pH}$ & 7.5 & 7.5 & 7 & 8 & 8 & 8 & $\mathrm{NO}$ & $\mathrm{NO}$ & & & $7.0-9.0$ \\
\hline Bilirrubin & M & $\mathrm{L}$ & - & - & - & - & NO & $\mathrm{NO}$ & & & - \\
\hline Density & 1.05 & 1.02 & 1.04 & 1.05 & 1.02 & 1.03 & $\mathrm{NO}$ & $\mathrm{NO}$ & & & $1.02-1.05$ \\
\hline \multirow[t]{2}{*}{ Ultrasound } & Cho & Cho & Cho & Cyst & Cho & Cho & Cho & Cho & & & \\
\hline & Fib & Fib & Fib & Fib & Fib & Fib & Fib & Fib & & & \\
\hline
\end{tabular}

The data are shown as mean $\pm \mathrm{SD}$. Mean $=$ Mean of the eight measurements, $\mathrm{SD}=$ Standard deviation, $\mathrm{CV}=$ Coefficient of variation. $\mathrm{RBC}$ : Red Blood Cells; ALP: Alkaline phosphatase; AST: Aspartate aminotransferase; GGT: Gamma-glutamyl transpeptidase; Creat: Creatinine; BUN: blood urea nitrogen; CK: Creatine phosphokinase; Glu: Glucose; -: negative; -/T=negative/trace; NO: Not obtained; Cho: Cholestasis; Fib: Fibrosis; RI=Reference interval; LRL=Low RI; URL=Upper RL; *RI, Robinson (2003); **RI, Wittwer (2012). 
higher than those described by Artz and Mount (1999). Other plants usually consumed by horses in Eastern Island tested negative for the presence of PAs (Börgel et al 2013). A significant and strong positive correlation between the MCT concentrations in C. grahamiana and liver biopsies $(\mathrm{r}=1.0)(\mathrm{H} 1-\mathrm{H} 8)$ was found. There is a strong suspicion of a causative relationship between $C$. grahamiana and hepatic encephalopathy in $\mathrm{CH}$, although this has not been definitively proven.

Based on the evidence presented in this study, including the observation of horses with $\mathrm{CH}$ ingesting $C$. grahamiana, clinical signs of hepatic encephalopathy, livers enlarged and congested, hepatic histopathological changes and strong positive correlation between MCT concentrations in $C$. grahamiana and liver biopsies, it is concluded that the most reasonable cause of $\mathrm{CH}$ is due to consumption of pyrrolizidine alkaloid-containing plants.

\section{ACKNOWLEDGEMENTS}

This work was funded by UNAB DI-399-13/I. The author thanks SAG and Conaf office in Rapa Nui.

\section{REFERENCES}

Albrecht J, Norenberg MD. 2006. Glutamine: a Trojan horse in ammonia neurotoxicity. Hepatology 44, 788-794.

Artz J, Mount M. 1999. Hepatotoxity associated with pyrrolizidine alkaloid (Crotalaria spp.) Ingestion in a horse on Easter Island. Vet Hum Toxicol 41, 96-99.

Börgel L, Lohse J, Ayerdi MT, Valenzuela L, Sunko D. 2013. Identification and determination of pyrrolizidine alkaloids: crotaline, heliotrine and retrorsine by infrared spectroscopy method in biological equine and environmental samples in Easter Island. Proceedings of XIII International Congress of Toxicology, Seoul, South Korea, Pp 2-66.
Botha CJ, Lewis A, Du Plessis EC, Clift SJ, Williams M. 2012. Crotalariosis equorum ("jaagsiekte") in horses in southern Mozambique, a rare form of pyrrolizidine alkaloid poisoning. J Vet Diagn Invest 24, 1099-1104.

Dubois A, Lenne P, Nahoe E, Rauch M. 2013. Plantas de Rapa Nui. Guía Ilustrada de la Flora de Interés Ecológico y Patrimonial. Umanga Mo Te Natura, CONAF y ONF International, Santiago. Chile.

Etienne M, Michel GE, Díaz E. 1982. Flora, vegetación y potencial pastoral de Isla de Pascua. Boletín Técnico 47, Facultad de Ciencias Agrarias, Veterinarias y Forestales, Universidad de Chile, Santiago, Chile.

Fu PP, Xia Q, Lin G, Chou MW. 2002. Genotoxic pyrrolizidine alkaloids - mechanisms leading to DNA adduct formation and tumorigenicity. Int J Mol Sci 3, 948-964.

Fuentes F. 1913. Reseña botánica sobre la Isla de Pascua. Boletín Museo Nacional de Historia Natural 5, 320-327.

Lecocq C, Moreira R. 2006. Reporte de un caso cuadro neurológico en equinos, Isla de Pascua, Chile. Salud Animal e Inocuidad de los Alimentos. División de Protección Pecuaria, Boletín Veterinario Oficial del SAG 7, 2-6.

Montoya MJ. 2011. Diagnóstico técnico y social de las prácticas ganaderas en Isla de Pascua. MOBA Consultora ambiental, Santiago, Chile.

Santos JC, Riet-Correa F, Simoes S, Barros C. 2008. Patogênese, sinais clínicos e patologia das doenças causadas por plantas hepatotóxicas em ruminantes e eqüinos no Brasil. Pesq Vet Bras 28, 1-14.

Stegelmeier BL, Edgar JA, Colegate SM, Gardner DR, Schoch TK, et al. 1999. Pyrrolizidine alkaloid plants, metabolism and toxicity. J Nat Toxins 8, 95-116.

Stegelmeier B. 2011. Pyrrolizidine Alkaloid-containing toxic plants (Senecio, Crotalaria, Cynoglossum, Amsinckia, Heliotropium, and Echium spp.). Vet Clin North Am Food Anim Pract 27, 419-428.

Stegelmeier B, Colegate SM, Brown AW. 2016. Dehydropyrrolizidine alkaloid toxicity, cytotoxicity, and carcinogenicity. Toxins (Basel) $8,356$.

Yan X, Kang H, Feng J, Yang Y, Tang K, et al. 2016. Identification of toxic pyrrolizidine alkaloids and their common hepatotoxicity mechanism. Int J Mol Sci 17, 318.

Yang X, Wang H, Ni HM, Xiong A, Wang Z, et al. 2017. Inhibition of Drp1 protects against senecionine-induced mitochondria-mediated apoptosis in primary hepatocytes and in mice. Redox Biol 12, 264-273. 